\title{
Communicating the relevance of paleo research in the current societal environment
}

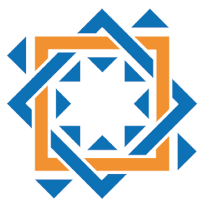

\author{
Heather Plumpton'1, E. Dearing Crampton-Flood² ${ }^{2}$ E.J. Gowan ${ }^{3}$, E.P. Dassié ${ }^{4}$
}

PAGES Morillo de Tou 2017

3rd Young Scientists Meeting

Global Challenges for our Common Future
It is not an easy task for paleoscientists to communicate the relevance of their research to policy makers and funders. However, an increase in catastrophic environmental calamities related to climate change (e.g. landslide, droughts, flooding) demands a response both in terms of policy-making and future governmental decisions. Often, climate change in the recent past was linked to major shifts in human behavior, which masks the relative contribution of humans and nature. For example, the $4.2 \mathrm{ka} \mathrm{BP}$ aridification event was so severe that it may have triggered the collapse of several large civilizations (the Old Kingdom in Egypt and the Akkadian Empire in Mesopotamia; Gibbons 1993). Compilations of long-term records of past variability can help reduce the uncertainties on past, present and future climate changes, and thus support informed societal decisions. Therefore, policymakers should (and some may argue, must) consider the long-term perspective provided by paleoscience research.

Better interaction with funding bodies and policy makers may also glean further information on how scientists can advocate for the relevance of paleo research. If we want politicians to engage with our science, we have to spend time with them and open a dialogue. Of course, this does not necessarily mean joining political demonstrations. In the past, scientists were part of high society - teachers and peers of politicians who could directly influence policy. While that is not the case anymore, it can be discussed if it is possible, or desirable, to replicate this kind of influence today. Scientists still have a duty to shape a debate by interacting with and informing politicians.

Contacting local representation, by email or post, before a bill is passed with focused, short and specific information, can help politicians forge their final decisions, and could be a first step towards establishing a long-term connection. It is extremely important to know one's audience and frame the communication accordingly, for example by addressing societal concerns such as jobs or water quality. Furthermore it may be helpful to engage optimistically by suggesting ways in which we can work with politicians to solve a problem.

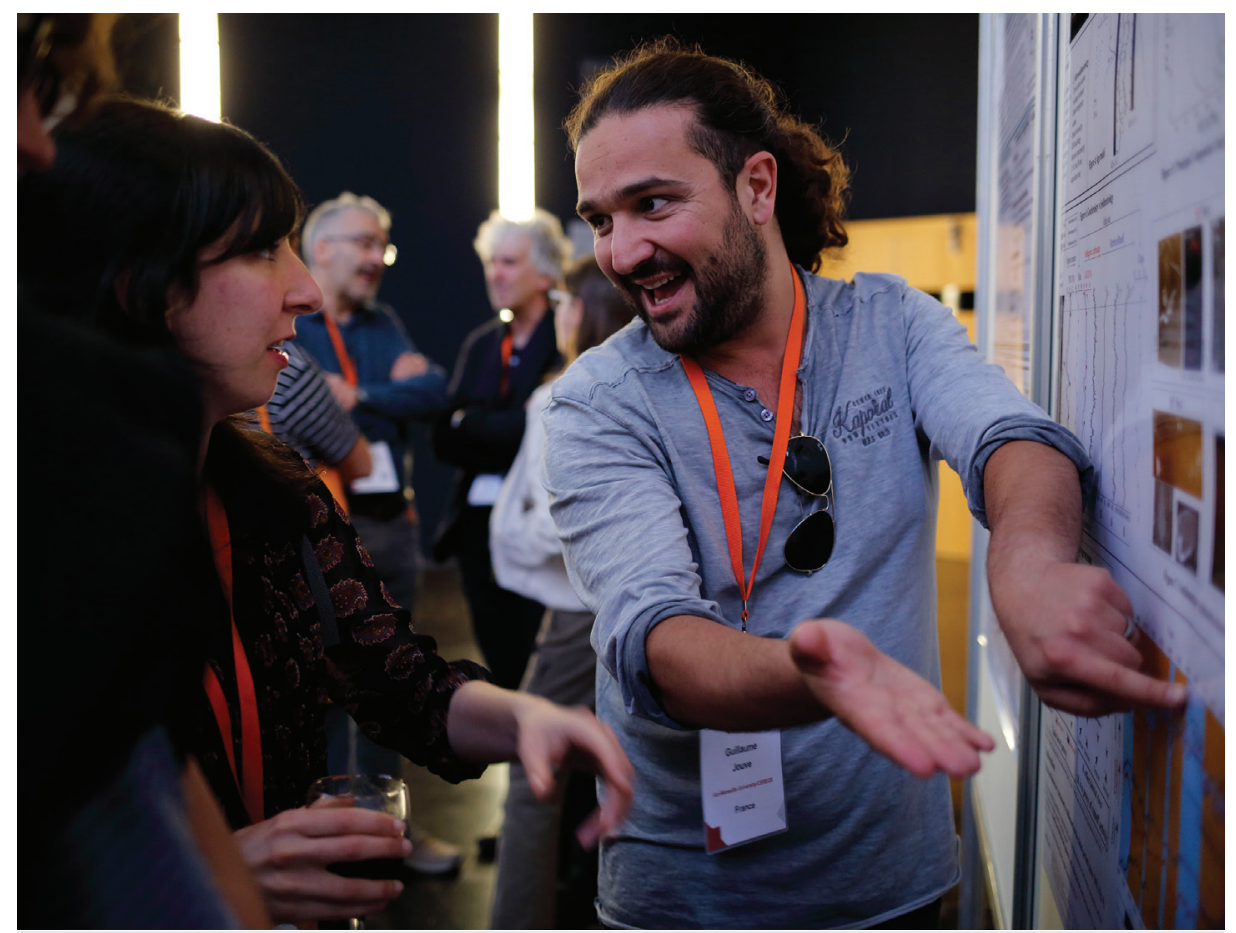

An animated Guilaume Jouve, from France, explains the relevance of his research.

A lively discussion within the scientific community is about whether scientists should (try to) fit their research into an application-based narrative in line with funding agencies and stakeholder expectations, or whether there are still opportunities to do fundamental basic science, or "science for the sake of science". Many funding agencies request research proposals, prior to any grant allocation, which demonstrate how the work will benefit society. This approach of research and science completely disregards the fact that fundamental science underpins all application-based science. More generally, funding applications should tell a compelling story that sets the proposal in the broader picture.

The synthesis of important paleoclimate data will enable policy makers to make more informed decisions with respect to climate change mitigation. We stress the need to address societal concerns when communicating to funding bodies stakeholders and policy makers, so the relevance of paleo research is appreciated by the wider community. We also highlight that advocating paleoclimate science is an exercise dependent on whoever is on the receiving end of the message.

\section{AFFILIATIONS}

'Department of Geography and Environmental Science, University of Reading, UK

${ }^{2}$ Department of Earth Sciences, Utrecht University, The Netherlands

${ }^{3}$ Paleo-climate Dynamics, Alfred Wegener Institute,

Bremerhaven, Germany

${ }^{4}$ LOCEAN/IRD, Paris, France

\section{CONTACT}

Heather Plumpton: H.Plumpton@pgr.reading.ac.uk

REFERENCES

Gibbons A (1993) Science 261: 985 